\title{
Stability and Risk of Financial Holding Companies-Taking the Chinese CITIC Group as Example
}

\author{
Juan Zhang \\ College of Economics, Jinan University, Guangzhou, China \\ Email: 13699725739@163.com
}

How to cite this paper: Zhang, J. (2019) Stability and Risk of Financial Holding Companies-Taking the Chinese CITIC Group as Example. Journal of Service Science and Management, 12, 246-266. https://doi.org/10.4236/jssm.2019.122017

Received: January 28, 2019

Accepted: February 24, 2019

Published: February 27, 2019

Copyright $\odot 2019$ by author(s) and Scientific Research Publishing Inc. This work is licensed under the Creative Commons Attribution International License (CC BY 4.0).

http://creativecommons.org/licenses/by/4.0/

c) (i) Open Access

\begin{abstract}
With the development of financial mixed operation, in order to enhance the financial competitiveness, more and more countries are accelerating the pace of from separate operation to mixed operation. Except bringing the advantages, financial holding company has also faced great challenges at the same time. Therefore, establishing the corresponding mixed supervision system and improving the competitiveness of the financial holding company have become the most important tasks for China's financial industry. Taking the Chinese CITIC International Financial Holdings Limited as an example, we focus on comparing economies of scale, economies of scope as well as the study of stability and risk, based on theoretical analysis and empirical analysis methods. The results show that most of the China Financial Holding Company Limited did not reach the greatest economies of scale and scope because of the restrictions on their own management and management experience. Secondly, the higher risk of securities will not increase the risk of major financial institutions such as banks. Thirdly, the risk of subsidiaries in financial holding companies is relatively low, compared with others in separated operation. In addition, we analyze the transmission mechanism and internal transaction risk of the financial holding company, innovatively propose "Incentive Conflict Concept" in subsidiary of internal and external risk control. Finally, the paper suggests that the financial holding companies should attach great importance to internal risk control, improve their management and integrated resource ability. More importantly, the external supervision mechanism needs to improve supervision mechanism design for the mixed supervision, as much as possible to achieve regulatory objectives of incentive compatibility.
\end{abstract}

\section{Keywords}

Financial Holding Firm, Mixed Financial Operation, Diminishing Risks, 
Incentive Conflicts

\section{Introduction}

In early 1990s, China used to implement the mixed financial operation. However, there were economic bubbles, which gradually continued to expand and internal risk transmission in the whole financial system caught the attention of regulator at the impact of domestic and aboard economic environment. China reformed the financial system by replacing mixed operation with separated operation from 1993. At that time, the separated operation was indeed a contribution to supervise and regulate financial market by the financial regulatory authorities, standardize the development of financial industry, also beneficial to maintain country's financial security and stability.

However, the development of global financial industry had a great change at late 1990s with the increasingly fierce competition in the international financial industry. The competition in the financial industry has developed from the single business of banks to the multi-field business. In order to adapt to the new changes in the international financial industry, many countries have speeded up the pace of changing from separated financial operation to mixed operation. Two biggest Banks in Germany, Deutsche Bank and Dresdner bank, have merged into a large financial holding company. In 1997, Japanese government announced "Financial System Reform Plan" to release financial control and introduce free competition market mechanism. Large financial institutions have come with the progress of setup, integration and incorporation that successfully made a huge contribution to the development of Japanese banks. The financial service modernization reform plan was passed at United States in November, 1999 that completely ended the independency of banking, security and insurance.

Reacting to the changed outlook, People's Bank of China issued the "interim provisions on intermediary business of commercial banks" in June 2001 that indicated that commercial banks were allowed to operate financial derivatives business such as investment banking and insurance business with permission by People's Bank of China, which provided the policy for the mixed operation under the separated financial industry system.

From historical experience of financial industry development and transformation, the mixed management has gradually become the inevitable trend of the world financial industry development. Mixed management not only provides the development of financial institutions in China, but also creates a huge challenge.

Financial holding company refers to a number of subsidiaries that operate different businesses under the control of one parent group. The innovative organizational form in the same time may bring special risks. In addition, the holding company is generally large in scale, with a wide range of businesses and close connections with other financial or non-financial institutions abroad. If a sub- 
sidiary crisis occurs, it will inevitably cause a certain impact on the whole financial holding company and the financial system, and even cause a large financial crisis. The bankruptcy caused by internal transactions of Barings bank in the past have made people deeply aware of the importance of risk management and institutional stability of financial holding companies, which will also be an important part of the work of financial holding companies and regulatory departments. Therefore, if we expect to adapt to the pace of mixed operation as soon as possible and improve the systems and development environment of financial holding companies, we urgently need to conduct an in-depth study of the real operation including the stability and risk, so as to provide guidance for the governance and development of financial holding companies in the next step.

Therefore, this paper innovatively fills the gap of empirical research, mainly based on the analysis of financial statements, taking China CITIC International Financial Holdings Limited as an example, discuss the stability and risk of its real operation, and provide reference value for the improvement of China's financial holding company management system and regulatory system.

\section{Literature Review}

\subsection{Definition \& Necessity of Financial Holding Company}

Some professors directly classify Financial Holding Companies as Mix-Operated Models completely and think that those two are completely equivalent. Ding Jun (2001) [1] mentioned that according to the definition of Financial Holding Company by BBS initiated by Basel Committee Of Banking Supervision, International Securities Federation and International Association Of Insurance Supervision, Financial Holding Company refers to a company that provides large-scale services in at least two or more different financial industries under the same control. Shen Lei (2012) [2] put forward that there are three types of models in current international financial mixed operation. Firstly, it is the universal banking, which has legally independent status and has different department providing all kinds of financial services in the interior, like Deutsche Bank; The second one is the Bank Holding Company, making a strict legal distinction between the parent company engaged in banking business and other subsidiaries engaged in non-bank business, and the non-bank business is operated by the subsidiaries. However, the firewall system existing in the parent and subsidiary company makes it harder to achieve the expected things. Last one is the Financial Holding Company, which is what we need to research. It means that under the control of the parent group, financial businesses such as banks, securities and insurances are respectively operated by different subsidiaries.

However, some professors believe that Financial Holding Companies are not equal to Mixed Operation, and the former is more advantageous in risk control. For example, Wen Hui (2003) [3] thought that Financial Holding Companies provide the opportunity for China to develop mixed operation within the existing laws of separated operation. The traits of Financial Holding Companies are 
"Mixed Operation of the parent group and separated operation of subsidiary company", meaning that the effective allocation of resources, cost reduction and efficiency improvement can be realized with various forms of cooperation such as equity control and capital of subsidiary company. At the same time, each subsidiary is operated separately, which is in line with the current system of separate supervision, and the respective supervision can supervise it more clearly. Therefore, the establishment and development of Financial Holding Company is the potential way for China's financial industry to go, and it will be great opportunity for China's financial industry to meet the challenges and enhance its comprehensive competitiveness. In general, this paper is more inclined to agree with Wen Hui (2003) [3], that is, Financial Holding Company is a composition of mixed operation and separated operation, rather than a simple mixed operation.

As for the necessity, Li Lin (2002) [4] pointed out that currently China's financial market has entered the buyer's market from the seller's market, and the demand of customer faced by enterprises plays the most important role in their competitiveness and vitality. At the same time, customers' demand for financial commodities gradually tends to be diversified, integrated and customized, that is, they expect to get comprehensive financial services in any institution, just like choosing financial commodities in the "financial supermarket". All these can only be achieved when the mixed operation is allowed. Therefore, if we want to improve the competitiveness of financial institutions, the mixed operation of financial industry has irreplaceable advantages.

What's more, scholars discuss about the positive effects existing in financial mixed operation. They have all unanimously proposed that it can not only improve efficiency and competitiveness, but achieve the goal of profit maximization while ensuring the overall safety and internal stability of the group. Separated operation focus more on risks, financial security, but the mixed management intend to improve the financial efficiency and strengthen risk control with it, allowing financial risk to go through internal management subsidiary. Shen Lei (2012) [2] proposed that because the parent company and the subsidiary have independent legal personality, they parent group can isolate certain risk transmission independently assume responsibilities and can isolate certain risk transmission.

Wen Hui (2003) [3] argues that there are good integration of resources and strain capacity in Financial Holding Company, providing customers with a full range of financially personalized and customized services, so as to consolidate subsidiaries good relations with customers.

\subsection{The Risk of Financial Holding Companies}

In China, scholars mainly study the risk measurement of financial holding companies in two ways. The first is to take the risk of single subsidiary into consideration and focus on the contribution of the subsidiary to the overall risk. Within a financial holding company, each sub-unit makes a corresponding contribution to the overall risk of the company. Therefore, it is believed that we should 
primarily assess the impact of a single financial subsidiary on the whole group. Li Zhihui, Li Yuan, Li Zheng (2015) [5] innovatively established a risk assessment system based on Shapley Value method, analyzing several factors which affects the degree of importance of financial subsidiaries and studying the internal risk structure of financial groups, Finally he concluded that the size was the key factor to the importance of subsidiaries in the whole group. The larger the size of the subsidiary, the greater the contribution to the overall risk of the financial holding group, which has great impact on the stability of the financial holding company.

White, an American economist, has also studied the risk degree of individual institutions and compared different types of institutional risks with each other. Taking the securities of financial holding company in the United States before 1933 as the researched object, it is found that the four profit indexes and coefficients of securities branches are higher than the corresponding data of Banks. However, White also found that the existence of securities branches or bond departments would either reduce the possibility of bank failure included in the sample or have no impact on it at all (Wu Jianwei, 2010) [6].

On the other hand, some scholars focus on the measurement method of the overall risk of financial holding companies on the theoretical level and construct the relative risk management framework. Introducing economic capital, Ruan Yongping (2011) [7] established the Hub Model measuring the overall risk measurement of financial holding companies by using the "chunking method". Liu Chunhang and Chen $\mathrm{Lu}$ (2009) [8] proposed to use Copulas function to sum risks on the type of corporation level, the company level and the group level, so as to obtain the risk of the whole banking group. Foreign economists Rosenberg and Schuermann (2006) [9] also proposed that Copula method could be used to synthesize the risks of bank holding companies, so as to determine the size of their overall risks.

As for the Risk categories, In February 1999, BBS mentioned in the final document on supervision of diversified financial groups that potential risks faced by financial holding companies include: capital adequacy ratio risk, capital double counting, capital arbitrage, high accumulation of risk, regulatory arbitrage, etc. The existing capital adequacy ratio is a separate measure for independent financial institutions, but BBS believes that this measure is not reliable under the mix-operated structure. Even if all individual financial institutions in the group meet the corresponding relative regulatory capital requirements, the capital at the group level may be insufficient. Therefore, the BBS focuses on the discussion on how to design the principles and methods to actually measure the capital adequacy ratio of various financial holding companies, and the requirements can truly reflect the risks of each subunit or each business. Its proposal should exclude the double calculation of capital within the company, which means that the same capital is used by two or more legal entities to resist risks, resulting in the leveraged amplification of capital outside the company. 
In China, Sun Xianfeng, Li Youhua (2005) [10] put forward that the internal subsidiaries of financial holding companies should not only face the risks arising from their own operation, but also face the characteristic risks caused by the complex ownership relationship. The most important risk for the regulatory authorities to pay attention to is the risk of internal trading, internal transmission of risk. Internal transactions mainly originate from the fund and profit transferred activities within the holding company, as well as from the purpose of tax avoidance or evasion of supervision, and eventually form a huge risk chain. When one of the subsidiaries has problems, it is easy to quickly spread to other subsidiaries or even external financial institutions. Zhang Zijuan (2008) [11] also puts forward the financial holding company internal factors such as related party transactions, cash flow, information flow, lead to the risk of financial holding companies become important aggregation point and the collection point, but Zhang Zijuan (2008) [11] focus more on the micro level, including the risk source, risk itself and risk pathways, to research risk mechanism of the financial holding company, providing many constructive theoretical basis for the subsequent risk control system.

\subsection{Summary}

In conclusion, the scholars mainly are interested in two aspects: the positive effects of financial holding companies and risk control of financial holding companies. They empirical data show us that there are scale economy and scope economy in the financial holding company. What's more, the existence of securities or other financial institutions can reduce the probability of bank management and improve the stability of the whole financial holding company, which means that the financial holding company could reduces the degree of risk compare to the separated organizations.

However, most of scholars' researches on financial holding companies' economies of scope and scale only focus on theoretical qualitative analysis, while less on quantitative analysis and data measurement. The pure theoretical positive effects are still insufficient to understand the situations of financial holding companies. Moreover, most scholars did research on internal risk of subsidiaries and fail to fully consider the incentive conflict between the supervision and management of the internal risk of subsidiaries and the external risk of the parent company. Therefore, this paper hopes to use financial statement data to study the scope economy and scale economy of financial holding company operation, and innovatively analyze the management and incentive conflicts existing in the holding company, filling in the gaps in previous research. It also provides a good empirical basis for the improvement of the management level of financial holding companies in the future. Therefore, this paper is of great value.

\section{Empirical Analysis and Theoretical Analysis of Financial Holding Companies}

Based on the above theoretical analysis and literature analysis, inspired by rele- 
vant empirical research, this paper takes CITIC International Financial Holdings Limited as an example and proposes three hypotheses:

Hypothesis 1: In the actual operation, the scale economy and scope economy of financial holding companies are not consistent with the theoretical value due to the limitation of management level, management experience and other factors.

Hypothesis 2: In actual operation, the stability of securities institutions is lower than that of bank institutions, but the existence of securities institutions does not increase the risk value of Banks.

Hypothesis 3: The Subsidiaries of financial holding companies have a relatively low probability of operational crisis compared with ordinary financial institutions with separated business operations.

\subsection{Abbreviations and Acronyms}

Showing in Table 1, we could know the abbreviations and acronyms, which would be easier for the reader to know which company we are talking about.

Table 1. Abbreviations and acronyms.

\begin{tabular}{|c|c|}
\hline The Index & The Abbreviations \\
\hline Return on personnel & ROP \\
\hline Management Fee/Total Revenue Ratio & MRR \\
\hline Ping An Bank Co., Ltd. & $\mathrm{PAB}$ \\
\hline Shanghai Pudong Development Bank Co., Ltd. & SPDB \\
\hline Hua Xia Bank Co., Limited & HXB \\
\hline China Minsheng Banking Corp., Ltd. & $\mathrm{CMBC}$ \\
\hline China Merchants Bank Co., Ltd. & CMB \\
\hline Industrial Bank Co., Ltd. & СIB \\
\hline Agricultural Bank of China Limited & $\mathrm{ABC}$ \\
\hline Bank of Communications Co., Ltd. & BCM \\
\hline Industrial and Commercial Bank of China Limited & $\mathrm{ICBC}$ \\
\hline China Everbright Bank Company Limited & CEB \\
\hline China Construction Bank Corporation & $\mathrm{CCB}$ \\
\hline Bank of China Limited & BOC \\
\hline China CITIC Bank Corporation Limited & CITICB \\
\hline Shenwan Hongyuan Group Co., Ltd. & SWHYS \\
\hline GF Securities Co., Ltd. & GFS \\
\hline Changjiang Securities Company Limited & CJS \\
\hline Guosen Securities Co., Ltd. & GSS \\
\hline First Capital Securities Co., Ltd. & FCS \\
\hline CITIC Securities Company Limited & CITICS \\
\hline
\end{tabular}




\section{Continued}

\begin{tabular}{cc}
\hline Haitong Securities Co., Ltd. & HTS \\
China Merchants Securities Co., Ltd. & CMS \\
China Securities Co., Ltd. & CS \\
The Pacific Securities Co., Ltd. & PS \\
Guotai Junan Securities Co., Ltd. & GTJAS \\
Industrial Securities Co., Ltd. & CIS \\
Huatai Securities Co., Ltd. & HTS \\
Everbright Securities Company Limited & EBS \\
China Galaxy Securities Co., Ltd. & CGS \\
Founder Securities Co., Ltd. & FS \\
Shenwan Hongyuan Group Co., Ltd. & SWHYS \\
GF Securities Co., Ltd. & GFS \\
Changjiang Securities Company Limited & CJS \\
\hline
\end{tabular}

\subsection{Testing the First Hypothesis: The Scale Effect and Scope Effect}

Theoretically, financial holding companies should enjoy good economy of scale from the perspective of managerial expense and financial expense. Economy of scale refers to the fact that, within a certain range, the average cost of production will keep falling as the scale of production expands. Some scholars put forward (Williams, 1985) [12] that the low resource specificity of the financial industry is conducive to saving managerial costs. Resource specificity refers to the difficulty or the cost of reallocating the resources that have been put into production. In short, the degree to which a resource is difficult to transfer from one use to another. From the perspective of managerial cost, when financial institutions continuously expand through mergers and acquisitions, resources need to be constantly transferred or redeployed among subsidiaries, and the low specificity of financial resources means that the lower the management cost of redeployment.

Economies of scope refer to financial institutions' access to a broader market and a multi-level and multi-range customer base. And cross-selling of related financial products is possible because they face the same fund crunchers and surplus earners (Fang Rufeng, 2001) [13]. In addition, the financial holding company has obvious advantages on capital and information, so the customer of subsidiary can be shared with other subsidiaries, jointly maintain relations with big clients, to provide low-cost diversified service portfolio, saving the cost of market channels to develop to a certain extent.

The theoretical benefits of economies of scope for banking can be formulated as follows:

According to Friedlaender, Winston and Wang, 1983, Economies of scope $=$ (banking independence costs + securities independence costs + trust independence costs + insurance independence costs + industrial independence costs - 
the cross costs of any two industries)/costs only in banking.

The specific cost of financial holding company, the parent group and subsidiaries, are difficult to obtain, so this paper chooses ROM and ROP to check whether the company reduce the average cost and get high returns, namely high economies of scale and scope economy, when they expand in scale and gradually grow into holding company. In order to enhance the credibility of the results, this paper picks 13 listed commercial Banks and 16 listed commercial securities companies as the objects. It is worth noting that few trust and insurance companies are listed, which is not conducive to comparative analysis, so this paper only takes CITIC Bank and CITIC Securities as the example. The data in this paper are all from the Wind, mostly from the annual report of each company.

Showing in Table 2 and Table 3, the bank subsidiaries, CITIC, CEB, PAB, the MRR and ROP of them are on the high side, ranking the second half of the 50\% range, respectively. For the MRR, came in sixth place (CITIC), seventh (CEB) and eleventh (PAB). For the ROP, came in sixth place (CEB), seventh (CITIC) and twelfth (PAB). Management Fee/Total Revenue (MRR) and Return on personnel (ROP) are the corresponding indicators reflecting scale effect and scope effect. The higher these ratios are, the higher the management cost will be and the lower scale effect will be. So the scale effect and scope effect of the three banks are not very up to the standard.

Showing in Table 4 and Table 5, the securities, CITICS, EBS, the MRR and ROP of them behave differently. For the MRR, fourth place (CITICS), tenth (EBS). For the ROP, they are great, coming in third place (CITICS), fourth (EBS). The scale effect and scope effect of securities are better than those of banks, even though it is just one of the indicators.

Table 2. Management fee/total revenue ratio (MRR) of 13 listed commercial banks.

\begin{tabular}{ccccccccccccccc}
\hline Rank & Bank & 2007 & 2008 & 2009 & 2010 & 2011 & 2012 & 2013 & 2014 & 2015 & 2016 & 2017 & Average \\
\hline 1 & ICBC & 0.34 & 0.30 & 0.33 & 0.31 & 0.29 & 0.29 & 0.28 & 0.27 & 0.25 & 0.26 & 0.24 & 0.29 \\
2 & SPDB & 0.37 & 0.37 & 0.36 & 0.33 & 0.29 & 0.29 & 0.26 & 0.23 & 0.22 & 0.23 & 0.24 & 0.29 \\
3 & CIB & 0.36 & 0.35 & 0.36 & 0.32 & 0.31 & 0.26 & 0.26 & 0.24 & 0.21 & 0.23 & 0.27 & 0.29 \\
4 & CCB & 0.36 & 0.31 & 0.33 & 0.31 & 0.30 & 0.29 & 0.29 & 0.28 & 0.26 & 0.25 & 0.26 & 0.29 \\
5 & BCM & 0.32 & 0.31 & 0.32 & 0.31 & 0.30 & 0.29 & 0.28 & 0.30 & 0.30 & 0.31 & 0.31 & 0.31 \\
6 & CITICB & 0.35 & 0.33 & 0.40 & 0.34 & 0.30 & 0.32 & 0.31 & 0.30 & 0.28 & 0.28 & 0.30 & 0.32 \\
7 & CEB & 0.32 & 0.34 & 0.39 & 0.35 & 0.32 & 0.30 & 0.32 & 0.30 & 0.27 & 0.29 & 0.32 & 0.32 \\
8 & BOC & 0.47 & 0.32 & 0.35 & 0.34 & 0.33 & 0.32 & 0.31 & 0.29 & 0.28 & 0.28 & 0.28 & 0.32 \\
9 & CMB & 0.35 & 0.37 & 0.45 & 0.40 & 0.36 & 0.36 & 0.34 & 0.31 & 0.28 & 0.28 & 0.30 & 0.35 \\
10 & CMBC & 0.46 & 0.43 & 0.42 & 0.39 & 0.36 & 0.34 & 0.33 & 0.33 & 0.31 & 0.31 & 0.32 & 0.36 \\
11 & PAB & 0.39 & 0.36 & 0.42 & 0.41 & 0.40 & 0.39 & 0.41 & 0.36 & 0.31 & 0.26 & 0.30 & 0.36 \\
12 & ABC & 0.34 & 0.45 & 0.43 & 0.39 & 0.36 & 0.37 & 0.36 & 0.35 & 0.33 & 0.35 & 0.33 & 0.37 \\
13 & HXB & 0.40 & 0.41 & 0.45 & 0.43 & 0.42 & 0.40 & 0.39 & 0.38 & 0.35 & 0.34 & 0.33 & 0.39 \\
\hline
\end{tabular}


Table 3. Return on personnel (ROP) of 13 listed commercial banks.

\begin{tabular}{cccccccccccccc}
\hline Rank & Bank & 2007 & 2008 & 2009 & 2010 & 2011 & 2012 & 2013 & 2014 & 2015 & 2016 & 2017 & Average \\
\hline 1 & BCM & 328 & 305 & 309 & 317 & 353 & 361 & 355 & 344 & 338 & 330 & 298 & 331 \\
2 & CIB & 273 & 277 & 332 & 380 & 319 & 368 & 314 & 350 & 317 & 283 & 272 & 317 \\
3 & ICBC & 208 & 273 & 276 & 309 & 310 & 319 & 327 & 323 & 318 & 320 & 317 & 300 \\
4 & CCB & 201 & 253 & 269 & 283 & 305 & 341 & 322 & 325 & 326 & 315 & 311 & 296 \\
5 & SPDB & 114 & 190 & 220 & 243 & 294 & 311 & 341 & 358 & 348 & 320 & 297 & 276 \\
6 & CEB & 267 & 164 & 201 & 235 & 281 & 299 & 286 & 278 & 276 & 374 & 264 & 266 \\
7 & CITICB & 273 & 240 & 213 & 285 & 339 & 270 & 295 & 258 & 295 & 223 & 190 & 262 \\
8 & CMB & 254 & 336 & 172 & 210 & 231 & 262 & 271 & 243 & 277 & 241 & 255 & 250 \\
9 & BOC & 0 & 0 & 244 & 266 & 277 & 280 & 292 & 297 & 288 & 275 & 271 & 249 \\
10 & CMBC & 150 & 132 & 171 & 212 & 238 & 269 & 299 & 267 & 252 & 240 & 241 & 225 \\
11 & HXB & 134 & 115 & 141 & 157 & 182 & 220 & 232 & 218 & 202 & 198 & 215 & 183 \\
12 & PAB & 177 & 30 & 185 & 203 & 189 & 208 & 185 & 185 & 189 & 236 & 191 & 180 \\
13 & ABC & 0 & 91 & 133 & 180 & 193 & 198 & 205 & 208 & 209 & 203 & 210 & 166 \\
\hline
\end{tabular}

Table 4. Management fee/total revenue ratio (MRR) of 16 listed securities.

\begin{tabular}{|c|c|c|c|c|c|c|c|c|c|c|c|c|c|}
\hline Rank & Security & 2007 & 2008 & 2009 & 2010 & 2011 & 2012 & 2013 & 2014 & 2015 & 2016 & 2017 & Average \\
\hline 1 & HTS & 0.29 & 0.42 & 0.37 & 0.46 & 0.46 & 0.44 & 0.44 & 0.35 & 0.29 & 0.34 & 0.35 & 0.38 \\
\hline 2 & GTJAS & 0.24 & 0.29 & 0.31 & 0.33 & 0.48 & 0.54 & 0.50 & 0.42 & 0.34 & 0.38 & 0.39 & 0.38 \\
\hline 3 & GFS & 0.16 & 0.14 & 0.29 & 0.41 & 0.53 & 0.53 & 0.52 & 0.44 & 0.41 & 0.45 & 0.44 & 0.39 \\
\hline 4 & CITICS & 0.31 & 0.38 & 0.36 & 0.38 & 0.32 & 0.50 & 0.50 & 0.48 & 0.36 & 0.45 & 0.39 & 0.40 \\
\hline 5 & GSS & 0.24 & 0.45 & 0.35 & 0.43 & 0.56 & 0.56 & 0.47 & 0.36 & 0.27 & 0.46 & 0.43 & 0.42 \\
\hline 6 & CMS & 0.31 & 0.42 & 0.38 & 0.35 & 0.46 & 0.55 & 0.50 & 0.43 & 0.39 & 0.41 & 0.46 & 0.42 \\
\hline 7 & SWHYS & 0.26 & 0.41 & 0.32 & 0.40 & 0.50 & 0.56 & 0.52 & 0.45 & 0.36 & 0.52 & 0.51 & 0.44 \\
\hline 8 & CS & 0.36 & 0.42 & 0.37 & 0.44 & 0.55 & 0.52 & 0.48 & 0.43 & 0.33 & 0.45 & 0.51 & 0.44 \\
\hline 9 & PS & 0.24 & -0.67 & 0.47 & 0.58 & 0.64 & 0.75 & 0.72 & 0.39 & 0.35 & 0.56 & 0.83 & 0.44 \\
\hline 10 & EBS & 0.23 & 0.40 & 0.31 & 0.39 & 0.48 & 0.61 & 0.64 & 0.47 & 0.35 & 0.52 & 0.53 & 0.45 \\
\hline 11 & HTS & 0.29 & 0.53 & 0.39 & 0.45 & 0.56 & 0.58 & 0.53 & 0.44 & 0.39 & 0.47 & 0.46 & 0.46 \\
\hline 12 & CGS & 0.33 & 0.47 & 0.32 & 0.46 & 0.57 & 0.61 & 0.53 & 0.51 & 0.43 & 0.46 & 0.50 & 0.47 \\
\hline 13 & CJS & 0.27 & 0.42 & 0.40 & 0.44 & 0.69 & 0.61 & 0.52 & 0.46 & 0.40 & 0.48 & 0.62 & 0.48 \\
\hline 14 & FS & 0.28 & 0.43 & 0.39 & 0.41 & 0.82 & 0.63 & 0.48 & 0.47 & 0.39 & 0.56 & 0.69 & 0.50 \\
\hline 15 & CIS & 0.25 & 0.55 & 0.42 & 0.51 & 0.64 & 0.67 & 0.62 & 0.49 & 0.42 & 0.59 & 0.60 & 0.52 \\
\hline 16 & FCS & 0.31 & 0.59 & 0.43 & 0.53 & 0.74 & 0.70 & 0.75 & 0.58 & 0.48 & 0.59 & 0.70 & 0.58 \\
\hline
\end{tabular}

Table 5. Rate on personnel (ROP) of 16 listed securities. 


\begin{tabular}{|c|c|c|c|c|c|c|c|c|c|c|c|c|c|}
\hline \multicolumn{14}{|c|}{ Continued } \\
\hline 3 & EBS & 448 & 219 & 500 & 374 & 248 & 144 & 35 & 143 & 238 & 131 & 127 & 237 \\
\hline 4 & CITICS & 332 & 258 & 259 & 341 & 322 & 147 & 117 & 171 & 189 & 128 & 171 & 221 \\
\hline 5 & CMS & 316 & 271 & 271 & 287 & 184 & 122 & 132 & 284 & 149 & 196 & 162 & 216 \\
\hline 6 & HTS & 517 & 128 & 269 & 198 & 143 & 112 & 125 & 191 & 263 & 207 & 202 & 214 \\
\hline 7 & CJS & 362 & 253 & 314 & 265 & 86 & 101 & 126 & 148 & 171 & 145 & 83 & 187 \\
\hline 8 & CGS & 343 & 180 & 325 & 179 & 123 & 101 & 117 & 118 & 137 & 149 & 117 & 172 \\
\hline 9 & SWHYS & $(0)$ & 224 & 345 & 240 & 168 & 124 & 128 & 170 & 189 & 111 & 118 & 165 \\
\hline 10 & CS & $(0)$ & 229 & 232 & 182 & 125 & 129 & 140 & 180 & 242 & 165 & 132 & 160 \\
\hline 11 & GSS & $(0)$ & 177 & 262 & 182 & 99 & 93 & 117 & 203 & 276 & 130 & 153 & 154 \\
\hline 12 & FS & $(0)$ & 238 & 275 & 245 & 48 & 83 & 137 & 158 & 163 & 116 & 73 & 140 \\
\hline 13 & GFS & 218 & 208 & $(60)$ & 125 & 135 & 110 & 118 & 149 & 164 & 162 & 173 & 137 \\
\hline 14 & PS & 812 & $(603)$ & 175 & 106 & 82 & 39 & 49 & 202 & 197 & 108 & 27 & 108 \\
\hline 15 & CIS & $(0)$ & 116 & 200 & 146 & 79 & 69 & 78 & 125 & 148 & 87 & 81 & 103 \\
\hline 16 & FCS & (0) & 108 & 174 & 123 & 49 & 54 & 44 & 89 & 130 & 107 & 61 & 85 \\
\hline
\end{tabular}

Combined with the above data analysis, it can be seen that the banking and securities subsidiaries of the financial holding companies have not reached the good scale effect in theory, and management expenses have no obvious advantages over other ordinary Banks or securities. It verifies the first hypothesis: In the actual operation, the scale economy and scope economy of financial holding companies are not consistent with the theoretical value due to the limitation of managerial level and experience and other factors.

This may be related to the development of China's financial holding companies, the lack of a complete management system and relative experience. In particular, the MRR and ROP of CEB and EBS rank in the end, which reminds them to pay attention to daily operation. In view of the current problems in management, they should come up with the solutions and focus on the allocation of resources to have the scale effect and improve the competitiveness of financial holding companies.

\subsection{Testing the Second Hypothesis: Stability of Subsidiaries in Financial Holding Companies}

The stock market crash in 1929, followed by the great economic crisis in 1933, led to the unprecedented downturn of the American economy. And then there was the Glass-Steagall Act, which ended the mixed operation of commercial banks and investment Banks. At that time, many economists believed that there were more risks in mixed operation, which eventually led to the financial crisis. However, many scholars have proved in different ways that financial mixed operation does not necessarily create high risks, but may reduce the overall risk to achieve the effect of mitigate risks.

American scholars Benston, Kroszner, Rajan et al. [6] have conducted empir- 
ical studies on risks and found no evidence that commercial banks who engaged in securities and investment would aggravate the possibility of their own failure or collapse of the financial system. Fengming Song (2000) [14] showed that between 1930 and 1933, the total proportion of bank failures was about 26.3\%, while the proportion of bank failures active in the securities sector was only $7.25 \%$. Other statistical analysis shows that when Banks have affiliated securities, the increased profitability strengthens the payment capacity of Banks, thus reducing the risk of bank failure, and thus reducing the risk of financial system crisis.

Meanwhile, American economist White has done a similar study and found that the four profit indicators and coefficients of securities are higher than the corresponding data of Banks. Moreover, the correlation coefficient of these indicators between banks and securities branches is not significant. So they concluded that banks with works in securities business will not have higher risks to the safety and stability of banks, for securities offer banks some potential diversification, even though within limits (Wu Jianwei, 2010) [6].

Inspired by method of White, this paper makes an empirical analysis of CITIC International Financial Holdings Limited to test last two hypotheses. Firstly, we test the correlation coefficient and variation coefficient between profit indicators of CITICB and CITICS, which could be used to observe the stability. If the correlation coefficient between them is not statistically significant, the profitability of the two does not affect each other, and the possibility of risk transmission decreases. What' more, the coefficient of variation is used to compare the degree of dispersion and volatility, and if the coefficient of variation is large, it indicates that the profit indicators fluctuate greatly and is unstable.

At last, we will test the risk value which could explain probability of operational crisis with the Z-Score.

CITIC International Financial Holdings Limited, including commercial banks and non-bank financial business, is a comprehensive and universal financial holding group. It can allocate the resources and establish the unified financially information platform to strengthen risk management and manage as well as coordinate the financial subsidiary development financial products, providing customers with comprehensive, one-stop financial services to enlarge financial holding group. The wholly state-owned limited company, was agreed to set up by the State Council and the People's Bank of China in 2002. In the long-term development process, it not only develops domestic business, but also attaches great importance to overseas business, building the international banking and capital business financial services brand. It is currently one of the leading financial holding groups that have good development compare with same type of business. Therefore the CITIC International Financial Holdings Limited in this paper is typical and has representativeness. At the same time, the CITIC Group has been set up for long time, so it has easier access to data, which is advantageous to the data analysis and processing. But for other financial holding com- 
panies, such as Pingan Group, its holding securities and banking industry's development, all in the position of the back, the process of development is not perfect, so this paper finally chose the comprehensive and representative CITIC Group whose result can reflect the development of China's financial holding group to some extent.

\subsubsection{The Correlation between Profit Indicators of CITICB and CITICS}

This paper selects the data of four profit indicators from 2007 to 2017 (note: since the annual report of 2018 is not updated, the data of 2017 is the latest data), which are: Return on equity (ROE, weighted); Net interest rate on total assets (NIR, annualized); Net profit/Total revenue; Operating profit/Total revenue.

The principal component analysis method (PCA), also known as the principal component analysis, was first proposed by Hotelling in 1933. With the idea of dimensionality reduction to convert multiple indicators into comprehensive indicators (also known as the principal component $\mathrm{F} 1$ variable) under the premise of least loss of information. Each $\mathrm{F} 1$ is a linear combination of original variables. Now we will convert four profit indicators which are showed in Table 6 and Table 7 for CITICB and CITICS into the principal component F1, which stands for the corporate profitability.

After the standardized processing of the data of the above four profit indicators of CITICB and CITICS from 2007 to 2017, the eigenvalues and eigenvectors are obtained.

Showing in Table 8, the cumulative contribution rate of the first two eigenvalues of CITICB reaches $94.88 \%$, while those of CITICS reaches $96.72 \%$,indicating that the first two components basically contain the information of profit indicator F1. By taking the first two eigenvalues and rotating the load matrix, the corresponding eigenvector can be obtained.

Table 6. Four profit indicators of CITICB \& CITICS.

\begin{tabular}{|c|c|c|c|c|c|c|c|c|}
\hline \multirow[b]{2}{*}{ Years } & \multicolumn{4}{|c|}{ CITICB } & \multicolumn{4}{|c|}{ CITICS } \\
\hline & ROE & NIR & $\begin{array}{c}\text { Net } \\
\text { profit/Total } \\
\text { revenue }\end{array}$ & $\begin{array}{c}\text { Operating } \\
\text { profit/Total } \\
\text { revenue }\end{array}$ & ROE & NIR & $\begin{array}{c}\text { Net } \\
\text { profit/Total } \\
\text { revenue }\end{array}$ & $\begin{array}{c}\text { Operating } \\
\text { profit/Total } \\
\text { revenue }\end{array}$ \\
\hline 2007 & 12.7 & 0.96 & 29.78 & 47.07 & 46.46 & 10.68 & 43.88 & 64.34 \\
\hline 2008 & 14.84 & 1.21 & 33.17 & 43.87 & 13.49 & 4.93 & 45.46 & 53.89 \\
\hline 2009 & 12.71 & 0.98 & 35.69 & 46.87 & 15.38 & 5.87 & 45.84 & 60.26 \\
\hline 2010 & 19.24 & 1.13 & 39.05 & 50.16 & 17.28 & 6.74 & 43.66 & 58.53 \\
\hline 2011 & 21.07 & 1.27 & 40.08 & 53.84 & 17 & 8.36 & 50.35 & 59.97 \\
\hline 2012 & 16.7 & 1.1 & 35.09 & 46.41 & 4.9 & 2.72 & 36.83 & 46.44 \\
\hline 2013 & 18.48 & 1.2 & 37.99 & 50.01 & 6.02 & 2.41 & 32.94 & 42.57 \\
\hline 2014 & 16.84 & 1.07 & 33.24 & 43.62 & 12.18 & 3.16 & 40.63 & 45.14 \\
\hline 2015 & 14.55 & 0.9 & 28.76 & 37.65 & 16.63 & 3.72 & 36.35 & 49.37 \\
\hline 2016 & 12.58 & 0.76 & 27.17 & 35.52 & 7.36 & 1.81 & 28.9 & 37.37 \\
\hline 2017 & 11.67 & 0.74 & 27.36 & 33.42 & 182 & 99 & 93 & 117 \\
\hline
\end{tabular}


Table 7. Summary statistics of the profit indicators used in the regression of CITICB \& CITICS.

\begin{tabular}{ccccccccc}
\hline \multicolumn{1}{c}{ CITICB } & \multicolumn{3}{c}{ CITICS } \\
\hline Stats & ROE & NIR & $\begin{array}{c}\text { Net } \\
\text { profit/Total } \\
\text { revenue }\end{array}$ & $\begin{array}{c}\text { Operating } \\
\text { profit/Total } \\
\text { revenue }\end{array}$ & ROE & NIR & $\begin{array}{c}\text { Net } \\
\text { profit/Total } \\
\text { revenue }\end{array}$ & $\begin{array}{c}\text { Operating } \\
\text { profit/Total } \\
\text { revenue }\end{array}$ \\
\hline mean & 15.58 & 1.03 & 33.40 & 44.40 & 12.92 & 4.76 & 39.32 & 50.49 \\
sd & 3.12 & 0.18 & 4.64 & 6.46 & 5.90 & 2.88 & 7.37 & 9.50 \\
min & 11.67 & 0.74 & 27.17 & 33.42 & 4.90 & 1.81 & 27.67 & 37.37 \\
max & 21.07 & 1.27 & 40.08 & 53.84 & 24.01 & 10.68 & 50.35 & 64.34 \\
$\mathrm{~N}$ & 11 & 11 & 11 & 11 & 11 & 11 & 11 & 11 \\
\hline
\end{tabular}

Table 8. The eigenvalues and eigenvectors of CITICB \& CITICS.

\begin{tabular}{|c|c|c|c|c|c|}
\hline $\begin{array}{l}\text { Component } \\
\text { Proportion }\end{array}$ & $\begin{array}{l}\text { Eigenvalue } \\
\text { Cumulative }\end{array}$ & Difference & $\begin{array}{l}\text { Component } \\
\text { Proportion }\end{array}$ & $\begin{array}{l}\text { Eigenvalue } \\
\text { Cumulative }\end{array}$ & Difference \\
\hline $\begin{array}{l}\text { Comp1 } \\
(0.8865)\end{array}$ & 3.54612 & 3.29696 & $\begin{array}{l}\text { Comp1 } \\
(0.8853)\end{array}$ & 3.54105 & 3.21314 \\
\hline $\begin{array}{c}\text { Comp2 } \\
(0.9488)\end{array}$ & 0.249162 & 0.108619 & $\begin{array}{c}\text { Comp2 } \\
(0.9672)\end{array}$ & 0.32791 & 0.234846 \\
\hline $\begin{array}{l}\text { Comp3 } \\
(0.9840)\end{array}$ & 0.140542 & 0.0763633 & $\begin{array}{l}\text { Comp3 } \\
(0.9905)\end{array}$ & 0.0930643 & 0.0550933 \\
\hline $\begin{array}{l}\text { Comp4 } \\
(1.0000)\end{array}$ & 0.0641791 & - & $\begin{array}{l}\text { Comp4 } \\
(1.0000)\end{array}$ & 0.037971 & - \\
\hline
\end{tabular}

Showing in Table 9, we could know the principal component for CITICB

First principal component: $\mathrm{F} 1=0.4841 \times 1+0.5029 \times 2+0.5132 \times 3+0.4994$ $\times 4$

Second principal component: F2 $=0.7976 \times 1-0.0574 \times 2-0.1246 \times 3-$ $0.5873 \times 4$

Third principal component: $\mathrm{F} 3=-0.1705 \times 1+0.8458 \times 2-0.4564 \times 3-$ $0.2174 \times 4$

Fourth principal component: F4 $=0.3168 \times 1-0.1687 \times 2-0.7161 \times 3+$ $0.5987 \times 4$

\section{For CITICS:}

First principal component: $\mathrm{F} 1=0.4872 \times 1+0.5118 \times 2+0.4782 \times 3+0.5214$ $\times 4$

Second principal component: $\mathrm{F} 2=-0.6136 \times 1-0.2562 \times 2+0.73076 \times 3+$ $0.1547 \times 4$

Third principal component: F3 $=0.6207 \times 1-0.6767 \times 2+0.3302 \times 3-$ $0.2186 \times 4$

Fourth principal component: $\mathrm{F} 4=0.0290 \times 1+0.4631 \times 2+0.3582 \times 3-$ $0.8102 \times 4$

For the expression of coefficient of CITICB and CITICS, we selected the first principal component as $\mathrm{F} 1$, four profit indicators and profitability have positive 
Table 9. Rotational load matrix eigenvectors of CITICB \& CITICS.

\begin{tabular}{cccccccccc}
\hline & \multicolumn{4}{c}{ CITICB } & \multicolumn{5}{c}{ CITICS } \\
\hline Variable & Comp1 & Comp2 & Comp3 & Comp4 & Variable & Comp1 & Comp2 & Comp3 & Comp4 \\
\hline x1 & 0.4841 & 0.7976 & -0.1705 & 0.3168 & $\mathrm{x} 1$ & 0.4872 & -0.6136 & 0.6207 & 0.0290 \\
x2 & 0.5029 & -0.0574 & 0.8458 & -0.1687 & $\mathrm{x} 2$ & 0.5118 & -0.2562 & -0.6767 & 0.4631 \\
x3 & 0.5132 & -0.1246 & -0.4564 & -0.7161 & $\mathrm{x} 3$ & 0.4782 & 0.7307 & 0.3302 & 0.3582 \\
$\mathrm{x} 4$ & 0.4994 & -0.5873 & -0.2174 & 0.5987 & $\mathrm{x} 4$ & 0.5214 & 0.1547 & -0.2186 & -0.8102 \\
\hline
\end{tabular}

correlation, while there are negative coefficients in other three principal component expressions, so only the first one meets the requirements.

Then we will have the KMO (Kaiser-Meyer-Olkin) test and SMC (Squared Multiple Correlations) test, to verify the effect of the above analysis. KMO is an important indicator used to measure the strength of the correlation between variables. It is obtained by comparing the coefficient of two variables and the partial correlation coefficient. The value of KMO is between 0 and 1 . The higher the value of $\mathrm{KMO}$, the stronger the similarity of variables and the more suitable for principal component analysis.SMC is the square of the composite correlation coefficient between a variable and all other variables, that is, the determined coefficient of the composite regression equation. A high SMC indicates that the stronger the linear relationship between variables, the stronger the similarity and the more suitable for principal component analysis.

Showing in Tables 10-12, the overall KMO value of CITICB is 0.7965 , and that of CITICS is 0.7718 . The SMC of the two is also high, which is suitable for principal component analysis.

The indicator weight is equal to the weighted average of the coefficient of the index in the linear combination of the principal components, with the variance contribution rate of the principal components as the weight. In this way, the weights and final profit indicators of CITICB and CITICS are calculated as follows.

Showing in Table 13, we could know the weight of each profit indicator and have the following F1 values of CITICB and CITICS which are showed in Table 14. Then we will use the correlation analysis to find the result about the hypothesis one.

Showing in Table 15, in the correlation analysis, the tested $\mathrm{P}$ value $=0.8836$, greater than the significance level of 0.05 , the null hypothesis is accepted, and there is no significant correlation. Therefore, the final conclusion is that there is no statistical correlation between the profitability of CITICB and CITICS. That is, the profitability of CITICB will not change due to the change in the profitability of CITICS, which is also consistent with the views of other predecessors.

\subsubsection{The Comparison of Stability of CITICB and CITICS}

In this paper, the coefficient of variation is used instead of the mean value, for the mean values of the two groups are far from each other, and the difference of 
Table 10. The way to determine whether the data is suitable for PCA.

\begin{tabular}{cc}
\hline Degree & $\mathrm{KMO}$ \\
\hline Marvelous & $0.9<\mathrm{KMO}<1.0$ \\
Meritorious & $0.8<\mathrm{KMO}<0.89$ \\
Middling & $0.7<\mathrm{KMO}<0.79$ \\
Mediocre & $0.6<\mathrm{KMO}<0.69$ \\
Miserable & $0.5<\mathrm{KMO}<0.59$ \\
Unacceptable & $0<\mathrm{KMO}<0.49$ \\
\hline
\end{tabular}

Table 11. Kaiser-Meyer-Olkin measure of sampling adequacy.

\begin{tabular}{ccc}
\hline Variable & CITICB & CITICS \\
\hline x1 & 0.8058 & 0.8636 \\
x2 & 0.8653 & 0.7895 \\
x3 & 0.7645 & 0.7493 \\
x4 & 0.7612 & 0.7105 \\
Overall & 0.7965 & 0.7718
\end{tabular}

Table 12. Squared multiple correlations of variables with all other variables.

\begin{tabular}{ccc}
\hline Variable & CITICB & CITICS \\
\hline x1 & 0.7722 & 0.8140 \\
x2 & 0.8220 & 0.9078 \\
x3 & 0.8959 & 0.8398 \\
x4 & 0.8644 & 0.9443 \\
\hline
\end{tabular}

Table 13. Weight cases of CITICB \& CITICS.

\begin{tabular}{ccc}
\hline Weight & CITICB & CITICS \\
\hline ROE & 0.8865 & 0.8417 \\
NIR & 0.0623 & 0.1380 \\
Net profit/Total revenue & 0.0351 & 0.0114 \\
Operating profit/Total revenue & 0.016 & 0.0089 \\
\hline
\end{tabular}

Table 14. The F1 value of CITICB \& CITICS.

\begin{tabular}{ccc}
\hline Years & CITICB & CITICS \\
\hline 2007 & 13.12 & 23.76 \\
2008 & 15.1 & 13.92 \\
2009 & 13.33 & 15.74 \\
2010 & 19.3 & 17.42 \\
2011 & 21.03 & 17.48 \\
2012 & 16.85 & 5.86 \\
\hline
\end{tabular}


Continued

\begin{tabular}{lcc}
\hline 2013 & 18.59 & 6.7 \\
2014 & 16.86 & 12.42 \\
2015 & 14.57 & 16.34 \\
2016 & 12.72 & 7.69 \\
2017 & 11.89 & 8.08 \\
\hline
\end{tabular}

Table 15. Correlation analysis of F1 in CITICB \& CITICS.

\begin{tabular}{cccc}
\hline & & CITICB & CITICS \\
\hline CITICB & Correlation & 1.000 & - \\
NIR & Significance & & 0.8836 \\
& Numbers & 11 & 11 \\
& Correlation & 0.0502 & 1.0000 \\
CITICS & Significance & 0.8836 & 11 \\
\hline
\end{tabular}

the mean value will seriously affect the accuracy of standard deviation comparison, so the coefficient of variation is used to measure the degree of dispersion (Coefficient Of Variation $=$ Standard Deviation/Mean Value).

Showing in Table 16, the variation coefficient of the four profit indicators of CITICS is higher than that of CITICB, which fluctuates around $0.1-0.2$, while that of CITICS fluctuates between $0.19-0.61$, which is larger than that of CITICB.

The analysis result of variation coefficient is similar to the result of American economist White, which is also in line with our second hypothesis: The stability of securities institution is lower than that of banking institution.

\subsection{Testing the Third Hypothesis: Comparison of Risks between Subsidiary of Financial Holding Companies and Generally Separated-Operation Institutions}

The Z-value analysis method is a widely used method to measure the bankruptcy risk invented by American scholar Altman. In this paper, financial institutions are studied. By referring to Roy (1952), Beck, Demirgii Kum and Levine (2010), $\mathrm{Z}$-score is introduced to measure the robustness of Banks in this way: Z-score = (ROA + Equity/Assets)/SD (ROA), ROA stands for the return on asset.

Showing in Table 17 and Table 18, the Z-Score of CITICB does not have an advantage over the four state-owned banks (BOC, ICBC, CCB and $A B C$ ). The higher the $\mathrm{Z}$ value is, the lower the bankruptcy risk will be; while the $\mathrm{Z}$-Score of CITICB is only in the middle. For securities, EBS ranks first, but CITICS is still in the middle, which does not show the advantage of risk control. Three, so refused to assume that financial holding company's subsidiaries, compared with generally separated-operation institutions, its probability of crisis will not necessarily low, this is consistent with the real situation in China, the four state-owned 
Table 16. Coefficient of variation.

\begin{tabular}{cccccccc}
\hline & \multicolumn{3}{c}{ CITICB } & \multicolumn{5}{c}{ CITICS } \\
\hline Profit & $\begin{array}{c}\text { Standard } \\
\text { Deviation }\end{array}$ & $\begin{array}{c}\text { Mean } \\
\text { Value }\end{array}$ & $\begin{array}{c}\text { Coefficient } \\
\text { of Variation }\end{array}$ & $\begin{array}{c}\text { Standard } \\
\text { Deviation }\end{array}$ & $\begin{array}{c}\text { Mean } \\
\text { Value }\end{array}$ & $\begin{array}{c}\text { Coefficient } \\
\text { of Variation }\end{array}$ & Difference \\
\hline ROE & 3.12 & 15.58 & 0.20 & 5.90 & 12.92 & 0.46 & 0.26 \\
NIR & 0.18 & 1.03 & 0.17 & 2.88 & 4.76 & 0.61 & 0.44 \\
$\begin{array}{c}\text { Net profit/Total } \\
\text { revenue } \\
\begin{array}{c}\text { Operating } \\
\text { profit/Total revenue }\end{array}\end{array}$ & 4.64 & 33.40 & 0.14 & 7.37 & 39.32 & 0.19 & 0.05 \\
\hline
\end{tabular}

Table 17. Z-Score of 13 listed commercial banks.

\begin{tabular}{cccccccccccccccc}
\hline Rank & Bank & 2007 & 2008 & 2009 & 2010 & 2011 & 2012 & 2013 & 2014 & 2015 & 2016 & 2017 & Average \\
\hline 1 & ICBC & 7.89 & 11.52 & 19.41 & 11.47 & 20.34 & 594.00 & 56.44 & 19.78 & 14.24 & 16.74 & 29.06 & 72.81 \\
2 & CCB & 10.63 & 16.91 & 31.13 & 12.21 & 17.76 & 343.06 & 53.86 & 17.87 & 11.54 & 14.11 & 33.35 & 51.13 \\
3 & ABC & 74.54 & 96.47 & 9.17 & 7.14 & 12.87 & 27.49 & 80.31 & 18.51 & 11.94 & 17.04 & 41.76 & 36.11 \\
4 & CIB & 36.31 & 28.93 & 26.72 & 33.11 & 35.63 & 65.32 & 42.61 & 14.79 & 9.90 & 16.22 & 45.43 & 32.27 \\
5 & BOC & 18.27 & 21.52 & 16.67 & 28.68 & 51.93 & 38.45 & 58.58 & 20.96 & 14.54 & 16.75 & 21.72 & 28.01 \\
6 & SPDB & 2.30 & 5.26 & 8.42 & 9.62 & 13.47 & 28.57 & 77.65 & 21.66 & 10.70 & 11.09 & 20.62 & 19.03 \\
7 & CMBC & 67.22 & 7.93 & 7.13 & 5.17 & 7.99 & 41.15 & 18.75 & 10.73 & 7.27 & 8.15 & 17.93 & 18.13 \\
8 & CMB & 20.95 & 6.32 & 4.56 & 6.18 & 9.01 & 38.81 & 16.19 & 10.46 & 12.19 & 36.61 & 28.31 & 17.23 \\
9 & BCM & 14.41 & 13.48 & 11.43 & 12.68 & 20.35 & 29.76 & 22.41 & 19.23 & 10.11 & 9.99 & 21.22 & 16.83 \\
10 & CEB & 6.76 & 9.80 & 7.04 & 5.33 & 10.12 & 44.97 & 43.28 & 15.79 & 7.71 & 7.96 & 18.36 & 16.10 \\
11 & CITICB & 6.02 & 9.40 & 9.01 & 8.20 & 14.27 & 13.11 & 17.53 & 7.48 & 6.22 & 9.19 & 65.94 & 15.12 \\
12 & HXB & 10.27 & 13.11 & 5.37 & 4.05 & 5.68 & 10.92 & 23.90 & 43.67 & 17.09 & 12.13 & 15.04 & 14.66 \\
13 & PAB & 1.78 & 0.42 & 2.12 & 18.17 & 19.61 & 11.28 & 17.96 & 20.40 & 13.45 & 9.72 & 14.45 & 11.76 \\
\hline
\end{tabular}

Table 18. Z-Score of 16 listed securities.

\begin{tabular}{ccccccccccccccccc}
\hline Rank & Security & 2007 & 2008 & 2009 & 2010 & 2011 & 2012 & 2013 & 2014 & 2015 & 2016 & 2017 & Average \\
\hline 1 & EBS & 1.89 & 0.67 & 4.33 & 2.60 & 4.22 & 1.86 & 0.89 & 1.24 & 3.01 & 1.00 & 232.45 & 23.11 \\
2 & HTS & 2.57 & 1.56 & 6.87 & 3.94 & 17.49 & 32.35 & 24.86 & 8.87 & 3.58 & 1.59 & 12.45 & 10.56 \\
3 & CIS & 1.67 & 0.37 & 2.93 & 1.53 & 4.04 & 9.22 & 5.63 & 3.55 & 3.38 & 1.24 & 55.34 & 8.08 \\
4 & GSS & 1.81 & 0.54 & 4.26 & 2.30 & 4.41 & 44.92 & 5.59 & 2.26 & 2.95 & 0.87 & 14.75 & 7.70 \\
5 & GTJAS & 4.62 & 4.04 & 4.03 & 1.88 & 5.12 & 11.77 & 7.15 & 3.13 & 5.13 & 2.84 & 29.11 & 7.17 \\
6 & GFS & 8.13 & 1.35 & -0.27 & 1.63 & 0.78 & 17.49 & 23.46 & 3.94 & 4.33 & 2.28 & 10.48 & 6.69 \\
7 & CMS & 2.12 & 1.00 & 4.62 & 2.35 & 4.79 & 9.53 & 10.21 & 3.09 & 3.69 & 1.64 & 20.63 & 5.79 \\
8 & CITICS & 2.70 & 1.73 & 6.82 & 5.70 & 3.08 & 0.97 & 7.32 & 5.16 & 4.03 & 1.94 & 20.93 & 5.49 \\
9 & SWHYS & 2.16 & 1.07 & 4.73 & 2.72 & 4.02 & 12.21 & 7.94 & 2.84 & 3.14 & 0.99 & 14.99 & 5.16 \\
10 & CGS & 2.21 & 1.13 & 3.55 & 1.71 & 5.95 & 5.22 & 8.74 & 4.73 & 3.89 & 1.56 & 9.00 & 4.34 \\
11 & HTS & 1.77 & 0.51 & 3.37 & 1.98 & 2.81 & 6.48 & 10.16 & 9.31 & 4.30 & 2.38 & 4.25 & 4.30 \\
\hline
\end{tabular}




\section{Continued}

\begin{tabular}{rccccccccccccc}
\hline 12 & CS & 3.77 & 3.24 & 5.06 & 2.17 & 4.00 & 6.09 & 7.65 & 2.68 & 4.07 & 1.69 & 4.00 & 4.04 \\
13 & FS & 3.20 & 2.22 & 6.53 & 1.83 & 0.82 & 2.09 & 5.67 & 11.67 & 4.11 & 1.54 & 2.41 & 3.83 \\
14 & CJS & 1.90 & 0.65 & 5.38 & 2.04 & 1.54 & 2.88 & 5.92 & 7.16 & 4.23 & 1.66 & 3.12 & 3.32 \\
15 & FCS & 1.75 & 0.50 & 3.83 & 2.05 & 1.77 & 9.46 & 2.28 & 2.91 & 3.92 & 1.60 & 4.70 & 3.16 \\
16 & PS & 0.80 & -0.85 & 0.71 & 1.21 & 3.31 & 2.55 & 0.81 & 2.90 & 2.25 & 0.94 & 0.51 & 1.38 \\
\hline
\end{tabular}

banks' funding abilities, such as the channels are stronger, while the bank of financial holding company is usually the stock-holding banks, the market share and funding abilities which is concerned with the liquidity are far away from the state-owned banks, so the risk of bankruptcy is relatively higher.

\section{Conclusions \& Suggestion}

\subsection{Conclusions}

With the development of the world economy, the financial industry has become the core part of economic development and financial innovation once again set off. In order to keep pace with the fierce competition, financial institutions have been accelerating their development from traditional separately-operated institutions to mixed operation. Based on the development of China's finance and relative regulation, financial holding company still is the only way to develop mixed operation, but financial risk and crisis warn us that the supervision should give enough attention to the financial holding company, such as the inner mechanism, in order to improve the operational efficiency of the financial holding company.

In this paper, on the basis of theoretical analysis and empirical research, taking the China CTTIC Group for example, what we could find is listed as:

1) Financial Holding Companies did not achieve scale effect and scope effect as in theory, the ROP and MRR of them ranked relatively low, there will be still great progress on management system.

2) The establishment of financial holding company can indeed improve the stability of the subsidiary to some extent. In this paper, the Z-Scores of CITICB and CITICS are higher than those of their counterparts, which means that the risk is lower.

3) The variation coefficient of securities' profit indicators is indeed higher than that of banks, but the addition of securities subsidiaries will not increase the operational risk of banks. This paper mainly uses principal component analysis, to calculate weight of the four profit indicators and convert them into the main factor (F1), the results show that although the coefficient of securities' profit indicators is higher than that of banks, the profitability of the securities was not associated with significant correlation with banks and that the addition of securities does not increase the risk of bank failure.

4) The complicated structure of financial holding companies as well as the 
sharing of internal transactions, cash flow and information resources, results in the special risk transmission mechanism. What's more, there is convergent effect in risk transmission, but that doesn't mean that the risk must be accumulated in the process of transmission, which depends on the risk control mechanism to a great extent.

\subsection{Suggestion}

Firstly, many financial institutions or industrial corporations are transforming themselves into financial holding companies through mergers and acquisitions in order to expand their business and enhance their competitiveness. Financial holding group is the great way for China to change from separate operation to mixed operation, and it is also one of the important developments. Therefore, the research on financial holding company has attracted more and more attention. Based on this paper, in the future, we could focus more on the microoperation. It means that we could do more research on the current development, such as whether its good scale economy and scope economy are up to standard. The data in this paper is still a bit limited, so the conclusion cannot be over generalized. So in the following-up studies, we should collect more data about their daily operation and make the comparison to analyze.

Secondly, incentives of risk control should be added into the salary assessment of the parent group to solve the incentive conflict. So in the future, with the empirical analysis, we could test whether the risk control could contribute to reducing risk, providing theoretical base for the establishment of risk management system in financial holding companies.

\section{Conflicts of Interest}

The author declares no conflicts of interest regarding the publication of this paper.

\section{References}

[1] Ding, J. (2001) Supervision of Financial Holding Companies in China under the Separate Supervision System. Studies of International Finance, 6, 58-61.

[2] Shen, L. (2012) On Mixed Operation and Mixed Supervision. Huazhong University of Science and Technology, Wuhan.

[3] Wen, H. (2003) Financial Holding Company: The Best Choice from Branch Industry to Mixed Industry. Economy and Management, 9, 38-39.

[4] Li, L. (2002) Practice of Mixed Operation under the Premise of Separate Operation System. Journal of Shengli Oilfield Staff University, 1, 11-13.

[5] Li, Z.H., Li, Y. and Li, Z. (2015) Research on Shapley Value-Based Comprehensive Operation Risk Assessment of Financial Holding Companies-A Case Study of China Everbright Group and CITIC Group. Nankai Economic Studies, 1, 32-50.

[6] Wu, J.W. (2010) A Brief Analysis of the Financial Industry Reform of China CITIC Group Corporation-Establishment of Finance as the Main Industry and Establishment of CITIC Group. Money China, 1, 92-95.

[7] Ruan, Y.P. (2011) Research on Financial Risk Management under Mixed Opera- 
tion-A Risk Measurement Model Application Based on Economic Capital. Management World, 7, 169-170 + 179 .

[8] Liu, C.H. and Chen, L. (2009) Risk Merger Table of Banking Group: Risk Measurement and Assessment Methods. Studies of International Finance, No. 2, 88-96.

[9] Rosenberg, J.V. and Schuermann, T.A. (2006) General Approach to Integrated Risk Management with Skewed, Fat-Tailed Risks. Journal of Financial Economics, 11, 113-127. https://doi.org/10.1016/j.jfineco.2005.03.001

[10] Sun, X.F. and Li, Y.H. (2005) Risk and Supervision Analysis of Related Party Transactions in Financial Holding Companies. China Economist, 11, 241-242.

[11] Zhang, Z.J. (2008) Research on Risk Transmission Mechanism and Control Countermeasures of Financial Holding Companies. Xi'an University of Technology, Xi'an.

[12] Williamson, O.E. (2007) The Economic Institutions of Capitalism. Firms, Markets, Relational Contracting. In: Boersch, C. and Elschen R., Eds., Das Summa Summarum des Managemen, Gabler, Wiesbaden, 61-75.

[13] Fang, R.F. (2001) Internal Mechanism, Risk and Supervision of Financial Holding Companies. Zhejiang University, Hangzhou.

[14] Song, F.M. and Xin, D. (2000) Rethinking on the Separate Operation System of Commercial Banks and Investment Banks. Journal of Financial Research, 1, 99-106. 